\title{
Testing decision-making competency of schizophrenia participants in clinical trials. A meta-analysis and meta-regression
}

\author{
Sorin Hostiuc ${ }^{1,2^{*}}$ D, Mugurel Constantin Rusu ${ }^{1}$, lonut Negoi ${ }^{1}$ and Eduard Drima ${ }^{3}$
}

\begin{abstract}
Background: The process of assessing the decision-making capacity of potential subjects before their inclusion in clinical trials is a legal requirement and a moral obligation, as it is essential for respecting their autonomy. This issue is especially important in psychiatry patients (such as those diagnosed with schizophrenia). The primary purpose of this article was to evaluate the degree of impairment in each dimension of decision-making capacity in schizophrenia patients compared to non-mentally-ill controls, as quantified by the (MacCAT-CR) instrument. Secondary objectives were (1) to see whether enhanced consent forms are associated with a significant increase in decision-making capacity in schizophrenia patients, and (2) if decision-making capacity in schizophrenia subjects is dependent on the age, gender, or the inpatient status of the subjects.

Methods: We systematically reviewed the results obtained from three databases: ISI Web of Science, Pubmed, Scopus. Each database was scrutinised using the following keywords: "MacCAT-CR + schizophrenia", "decision-making capacity + schizophrenia", and "informed consent + schizophrenia."
\end{abstract}

Results: We included 13 studies in the analysis. The effect size between the schizophrenia and the control group was significant, with a difference in means of $-4.43(-5.76 ;-3.1, p<0.001)$ for understanding, $-1.17(-1.49,-0.84, p<0.001)$ for appreciation, $-1.29(-1.79,-0.79, p<0.001)$ for reasoning, and $-0.05(-0.9,-0.01, p=0.022)$ for expressing a choice.

Conclusions: Even if schizophrenia patients have a significantly decreased decision-making capacity compared to non-mentally-ill controls, they should be considered as competent unless very severe changes are identifiable during clinical examination. Enhanced informed consent forms decrease the differences between schizophrenia patients and non-mentally-ill controls (except for the reasoning dimension) and should be used whenever the investigators want to include more ill patients in their clinical trials. Increased age, men gender and an increased percentage of inpatients might increase the differential of decision-making incompetence compared to nonmentally-ill subjects in various dimensions of the decision-making competence as analysed by the MacCAT-CR scale, but the small number of subjects did not allow us (except for one instance) to reach statistical significance.

Keywords: Informed consent, Schizophrenia, MacCAT-CR

\footnotetext{
* Correspondence: soraer@gmail.com; sorin.hostiuc@umfcd.ro

${ }^{1}$ Carol Davila University of Medicine and Pharmacy, Sos.Vitan Barzesti 9,

042122 Sector 4, Bucuresti, Romania

${ }^{2}$ National Institute of Legal Medicine, Bucharest, Romania

Full list of author information is available at the end of the article
} 


\section{Background}

Schizophrenia patients, as a group, are considered less able to give a proper consent for either specific medical procedures, or for their inclusion in clinical trials, because they tend to have a decreased capacity to understand, retain and process relevant information [1]. However, various studies suggested that many patients with this illness, even in the acute phase, have an intellectual capacity averaging the one found in the general population. Moreover, once the treatment begins, many deficits are significantly diminished; therefore, some authors consider that the decision making capacity analysis should be mandatory and done multiple times during the course of the treatment [2]. In average, Jeste found that between 10 and 52\% of schizophrenia patients do not have insight [3]. The absence of decisionmaking capacity (DMC) is more important in hospitalized patients [3], if they are in a psychotic state, or if they have a decreased educational level [4].

The process of assessing the DMC of potential subjects before their inclusion in clinical research is a legal requirement and a moral obligation, being essential for respecting their autonomy. The degree of impairment that can render a subject incompetent to participate in a clinical trial should, ideally, reflect a societal judgement about reaching a proper equilibrium between its autonomy and protection as a vulnerable subject [5].

DMC is a four-dimensional concept, which includes (1) the understanding of the disclosed information, (2) its appreciation of a particular setting, (3) the reasoning associated with that information and (4) the aptitude to express a choice [6]. DMC is highly dependent upon the capacity of an individual to choose a specific course of action voluntarily $[1,6,7]$ (including the participation to a clinical trial). The choice whether to enter a clinical trial should be fully autonomous. Full autonomy is presumed in adults, unless there are circumstances that can cause a partial or total loss of their capacity to act autonomously (the presence of dementia, schizophrenia or other psychiatric disorders, prisoners, persons with a low socioeconomic status, and so on) [8-10].

Schizophrenia patients have quantitative and qualitative mental deficits, classified in three main categories: cognitive, negative (associated with the disruption of normal behaviours and emotions) and positive (psychotic) symptoms. Their presence can potentially lead to an incorrect assessment of a request to participate in a clinical trial [11]. Howe et al., for example, found that DMC is inversely correlated with specific positive symptom factor scores, especially those associated with cognition (poor attention, difficulty in abstract thinking and conceptual disorientation) [12]. Moser et al. found that patients with positive symptoms do not have significant impairments on any MacArthur Competence Assessment Tool for Clinical Research (MacCAT-CR) subscale, while patients with negative and disorganised symptoms have a decreased DMC [13]. Overall, a larger proportion of people with schizophrenia has a significant degree of decision-making impairment compared to non-mentally-ill subjects [3]. Some studies suggest that various factors such as age, gender or impatient status could alter DMC $[9,14,15]$.

The MacCAT-CR instrument is often used to assess the DMC for taking part in clinical research of schizophrenia subjects. It is a 20- to 30-min semi-structured interview, which analyses the four main dimensions of decisionmaking capacity, each of them receiving a particular score - 0-26 points for understanding, 0-6 points for appreciation, $0-8$ points for reasoning and $0-2$ points for expressing a choice [16].

Most studies that compared DMC of schizophrenia subjects versus non-mentally-ill controls, by using the MacCAT-CR instrument, found significant decreases in one or more of its main dimensions [13, 15, 17-22]. The mean score for each dimension and the score difference between the subgroups was variable. A meta-analysis performed by Wang et al. analysed the decisional capacity measured by MacCAT tools in schizophrenia patients; however, it failed to include many studies, and it did not test specifically decisional capacity for participating in clinical trials [23]. Enhanced informed consent forms are often use to increase the capacity of the patients to understand relevant information about their medical condition and the proposed medical interventions [24-26], including schizophrenia patients [25].

The primary aim of this article was to test the impairment in each dimension of DMC in schizophrenia patients compared to non-psychiatric controls, as appraised by the MacCAT-CR instrument. Secondary objectives were (1) to see whether enhanced informed consent (EIC) is associated with a significant increase in DMC in schizophrenia patients, and (2) if the DMC in schizophrenia subjects depends on the age, gender, their inpatient status, or country of origin.

\section{Methods}

We performed the study according to the PRISMA and MOOSE guidelines for reporting systematic reviews and meta-analyses of observational studies in epidemiology.

\section{Selection criteria}

Inclusion criteria: (1) observational studies that analysed the DMC of schizophrenia subjects compared to a control group comprising of non-mentally-ill subjects, with the aid of the MacCAT-CR instrument. The main exclusion criteria were: (1) not fulfilling the inclusion criteria, (2) not presenting enough information to reconstruct the data needed for the analysis, (3) case-series studies and studies without a control group. 


\section{Search method.}

We analysed the results found in three databases: ISI Web of Science, Pubmed, Scopus. For each, we used the following keywords: "MacCAT-CR + schizophrenia", "decision-making capacity + schizophrenia", and "informed consent + schizophrenia",

\section{Data collection and analysis}

Two authors researched the databases independently, with an agreement rate for the added articles of $83.3 \%$. Data was then extracted separately by the two reviewers and listed in an Excel file. When we found discrepancies between the obtained results, the issues were re-analyzed by both examiners. We summarized the following data: study, year, total number of cases, mean age and standard deviation, gender ratio for each group, ratio of in- versus outpatients in the cases group, and mean and standard deviation of the values in the four main dimensions of MacCAT-CR - understanding, appreciation, reasoning and expressing a choice. If a particular article contained data regarding a potential intervention aimed at improving the DMC, we added the data for both unenhanced and enhanced informed consent techniques/forms.

The risk of bias was assessed separately for each case.

The quality assessment was performed by two researchers using the Newcastle-Ottawa Scale for case-control studies (NOS) [27]. NOS was developed to address the quality of non-randomized studies for systematic reviews/meta-analyses. Briefly, it comprises of eight items, categorised into three main groups: (1) selection of the survey groups, (2) comparability of the two groups and (3) evaluation of the exposure or outcome of interest. The final quality score was computed as an average of the scores given by the two reviewers. The agreement rate between reviewers was $90 \%$.

\section{Statistical analysis}

We determined the effect size as the difference in means in all cases using a random effects model computed in Comprehensive Meta-analysis software. To assess the odds for significant alterations of the dimensions of the DMC, we calculated the Odds Ratio (OR). This was done by transforming the difference in means in Cohen's d (by dividing it by the standard deviation), converting Cohen's $d$ into $\ln (\mathrm{OR})$ through the following formula $\ln (\mathrm{OR})=\mathrm{d} \pi / \mathrm{sqrt}(3)$, and then $\ln (\mathrm{OR})$ to OR through the following eq. $\mathrm{OR}=\mathrm{e}^{\ln (\mathrm{OR})}$. For each group and subgroup, we performed a forest plot. We used Egger's intercept technique for the analysis of publication bias, and $\mathrm{I}^{2}$ for measuring the heterogeneity. For comparison of the effect size between two groups, we used the Z-test. We used 95\% confidence intervals and considered a $p$-value of 0.05 or lower to be statistically significant. We rounded the obtained values to the second decimal, except for (1) $p$-values below 0.05 , case in which we included data until the 4th decimal, (2) when by rounding, the value was below 0.01 and (3) when by rounding the OR, we obtained the value 1 .

\section{Results}

\section{Search synthesis}

We obtained 2496 results from which, after deleting duplicate and irrelevant studies and analysing the type of paper and abstracts (if available), 56 articles were selected. They were downloaded and examined further. Evaluating the references of these 53 articles, we identified seven more that were considered potentially relevant, which were also downloaded. From the total number of 60 studies, we selected 13, which ultimately fulfilled the inclusion criteria, and were added to the meta-analysis (with the except of the "expressing a choice" subscale, where there were only 10 studies with relevant information). We excluded 47 articles for not meeting the inclusion criteria. Details regarding the selection algorithm are shown in Fig. 1. The studies included in the analysis are described in detail in Table 1.

\section{Quality assessment}

The studies had quality scores ranging from 4.5 to 6.5 using the NOS Case Control scale. The values for each study are presented in Table 1.

\section{Descriptive data}

Within the 13 included studies were 684 schizophrenia subjects (582 in standard consent studies and 102 in enhanced consent studies), and 458 subjects in the control groups (389 in standard consent studies and 69 in enhanced consent studies). The arithmetic mean values for the four dimensions of the MacCAT-CR test are presented in Table 2. Eleven studies were performed in the US and two outside US (one in China, and one in Colombia).

\section{Understanding}

The effect size between the schizophrenia subjects and the control group was significant, with a difference in means of $-4.43(-5.76 ;-3.1), p<0.001$. The odds for a decreased understanding in schizophrenia patients was about five times higher compared to control groups $(\mathrm{OR}=0.18$, $\mathrm{CI}=0.12-0.29, p<0.001)$. See Fig. 2 for details. Publication bias was not statistically significant (Egger's regression intercept $=-2.6, p=0.17$ ). The heterogeneity of the understanding dimension was low $\left(\mathrm{I}^{2}=9.84 \%\right)$.

By running a meta-regression using mean age, percent of men and percent of inpatient status as covariates, we could not find any statistically significant effects (see Table 3). The difference between mean values for understanding in cases versus control groups was larger for studies conducted outside the US $(-4.67$, with limits between -12.16 and 2.836) compared to studies 


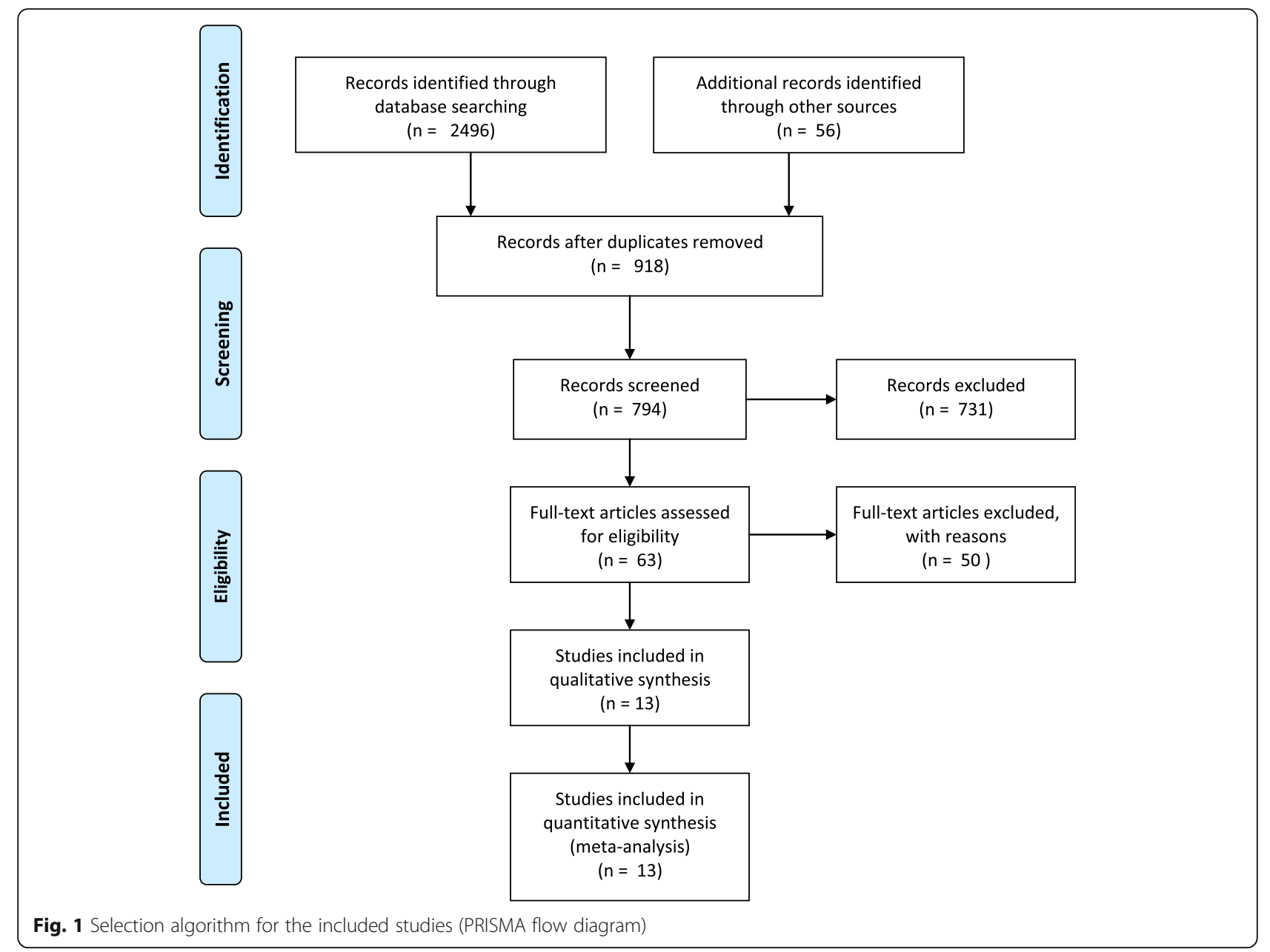

performed in the US $(-3.941$, with limits between -5.02 and -2.86$)$. The difference was statistically significant $(\mathrm{Z}=-7.26, p<0.001)$.

Three studies contained information about enhanced informed consent. In them, we found a decreased difference in means compared to controls $(-2.73$, with limits between -4.97 and -0.49 ). The odds for a decreased understanding in schizophrenia subjects using EIC was almost four times higher compared to the control groups $(\mathrm{OR}=0.28, \mathrm{CI}=0.14-0.59, p=0.001)$.

The use of EIC leads to a significant increase in understanding in schizophrenia subjects compared to standard informed consent forms $(\mathrm{Z}=-13.34, p<0.001)$.

\section{Appreciation}

The effect size was significant, with a difference in means of $-1.17(-1.49,-0.84, p<0.001)$. The odds for a decreased appreciation in schizophrenia patients was about five times higher compared to the control groups $(\mathrm{OR}=0.20, \mathrm{CI}=0.14-0.28, p<0.001)$. See Fig. 3 for details. Publication bias was not statistically significant
(Egger's regression intercept $=1.51, p=0.16$ ). The heterogeneity of the appreciation dimension was very low $\left(\mathrm{I}^{2}=5.79 \%\right)$.

By running a meta-regression using mean age, percent of men and percent of inpatient status as covariates, we could not find any statistically significant effects (see Table 3 ). The difference between mean values for appreciation in the cases versus control groups was larger for studies conducted outside the US $(-1.15$, with limits between -2.23 and -0.08$)$ compared to studies performed in the US $(-1.01$, with limits between -1.31 and -0.72$)$. The difference was statistically significant $(\mathrm{Z}=-7.021, p<0.001)$.

Three studies contained information about EIC. In them, we found a decreased difference in means compared to controls $(-0.46$, with limits between -0.76 and -0.15$)$.

The use of EIC leads to a significant increase in appreciation in schizophrenia subjects compared to standard informed consent forms $(\mathrm{Z}=-12.525, p<0.001)$.

\section{Reasoning}

The effect size was highly significant, with a difference in means of $-1.29(-1.79,-0.79, p<0.001)$. The odds for 
Table 1 Summary of studies included in the meta-analysis

\begin{tabular}{|c|c|c|c|c|c|c|c|}
\hline Study & $\begin{array}{l}\text { Total } \\
\text { No Subjects }\end{array}$ & $\begin{array}{l}\text { Schiz. } \\
\text { Subjects }\end{array}$ & $\begin{array}{l}\text { Control } \\
\text { group }\end{array}$ & $\begin{array}{l}\text { Mean age } \\
(\text { St dev })^{\mathrm{a}}\end{array}$ & Men\% ${ }^{\mathrm{a}}$ & Description & Quality $^{c}$ \\
\hline 2008, Candillis [18] & 109 & 52 & 57 & $\begin{array}{l}37.79(11.67), \\
41.04(13.16)\end{array}$ & $\begin{array}{l}76.9 \\
57.9\end{array}$ & $\begin{array}{l}\text { Subjects: } 45 \text { stable patients from a state hospital, } \\
\text { seven outpatients. Controls: patients from a diabetes } \\
\text { clinic Answers were given regarding the participation to a } \\
\text { potential drug trial; payment of } 10 \$ \text { per participation }\end{array}$ & 5 \\
\hline 2000, Carpenter [19] & 54 & 30 & 24 & $\begin{array}{l}40.2(8.8) \\
39.7(10.2)\end{array}$ & $\begin{array}{l}56.7 \\
78.2\end{array}$ & $\begin{array}{l}\text { Subjects: inpatients and outpatients ( } 20 \text { and } 10 \text { respectively). } \\
28 \text { schizophrenia patients, } 2 \text { patients with schizoaffective } \\
\text { disorder. Controls: recruited from community centres and a } \\
\text { free medical clinic. Answers regarding the participation to a } \\
\text { randomised, double-blind trial for a novel } \\
\text { anti-psychotic medication }\end{array}$ & 5 \\
\hline 2004, Cohen [34] & 26 & 6 & 20 & $\begin{array}{l}40.0(7.8) \\
41.1(10.3)\end{array}$ & $33.3,60$ & $\begin{array}{l}\text { Subjects: } 6 \text { inpatients. Controls: community volunteers } \\
\text { Answers: regarding two studies - a drug study, and a } \\
\text { ketamine study. We averaged the values of the two studies } \\
\text { for each MacCAT CR subscale }\end{array}$ & 5 \\
\hline
\end{tabular}

$\begin{array}{lcccl}\text { 2012, Harmell [20] } & 17 & 9 & 8 & 57(10), \\ & & & & 52.2(12.1) \\ & & & & \\ & & & & \\ \text { 2012, Harmell [20] } & 18 & 10 & 8 & 57.9(8.9), \\ & & & & 48.6(15.9) \\ \text { 2009, Jeste [21] } & 95 & 66 & 29 & 51.2(6.5), \\ & & & & 54.2(9.3)\end{array}$

89, 50 Subjects: outpatients, recruited through a registry; randomly assigned for receiving either a normal or a web-media enhanced consent procedure. Controls: non-psychiatry patients, recruited through a registry Answers: regarding a hypothetical clinical trial for an experimental cognition enhancing medication

Subjects: community-dwelling outpatients aged $>40$ years,

with schizophrenia. Subjects were randomly assigned to either a standard or a multimedia consent procedure. Controls: recruited through newspaper advertisements, flyers, or word of mouth Answers: regarding a 14-week double-blind, placebo-controlled RCT to determine the effectiveness of a cognition-enhancing drug for cognitive deficits associated with schizophrenia or with normal ageing

$\begin{array}{lcccl}\text { 2009, Jeste [21] } & 93 & 62 & 31 & 52.4(8), \\ & & & & 54.7(7.3) \\ \text { 2007, Kim [22] } & 131 & 91 & 40 & 42.2(10.2), \\ & & & & 39.9(10.9)\end{array}$

65,45

Subjects: with severe mental illness consisted of two subgroups: 55 participants from a schizophrenia study from six different sites across the US; 36 people from two outpatient clinics serving individuals with severe and persistent mental illnesses, and from inpatient units. Controls: recruited through advertisements from the community, in support staff work areas of a general hospital and at an out-patient substance misuse recovery program Answers: regarding participation in the CATIE study

\begin{tabular}{|c|c|c|c|c|}
\hline 2003, Kovnick [15] & 51 & 27 & 24 & $\begin{array}{l}39.1(7.1) \\
39.7(10.2)\end{array}$ \\
\hline $\begin{array}{l}\text { 2016, } \\
\text { López-Jaramillo [35] }\end{array}$ & 120 & 80 & 40 & $\begin{array}{l}34.9(10.5) \\
37(14.3)\end{array}$ \\
\hline 2006, Moser [36] & 60 & 30 & 30 & $\begin{array}{l}34.1(10.65), \\
30(11.46)\end{array}$ \\
\hline 2006, Moser [36] & 60 & 30 & 30 & $\begin{array}{l}34.1(10.65) \\
30(11.46)\end{array}$ \\
\hline 2002, Moser [13] & 50 & 25 & 25 & $\begin{array}{l}31.56(9.77) \\
37.4(7.76)\end{array}$ \\
\hline
\end{tabular}

Cases: 27 psychiatric inpatients, non-acutely ill. Controls: individuals from the community, without known psychiatric pathologies Answers regarding a hypothetical randomized, double blind trial for a new schizophrenia drug

Cases: 80 individuals with schizophrenia. Controls: healthy volunteers Answers regarding the participation to a clinical trial

Cases: 30 individuals with schizophrenia (6 outpatients, 24 inpatients). Controls: healthy individuals, without significant psychiatric or medical pathologies Answers regarding a possible double-blind, placebo-controlled trial of a cognitive-enhancing agent called Synaptoclear

Cases: 25 individuals with schizophrenia, 21 outpatients, and four inpatients, 18 of which received antipsychotic medication. Controls: 25 infected individuals, 24 outpatients, one inpatient, 15 under psychotropic medication (primarily for depression); none was under antipsychotic medication Answers regarding a hypothetical 6-week, randomised, 
Table 1 Summary of studies included in the meta-analysis (Continued)

\begin{tabular}{|c|c|c|c|c|c|c|c|}
\hline Study & $\begin{array}{l}\text { Total } \\
\text { No Subjects }\end{array}$ & $\begin{array}{l}\text { Schiz. } \\
\text { Subjects }\end{array}$ & $\begin{array}{l}\text { Control } \\
\text { group }\end{array}$ & $\begin{array}{l}\text { Mean age } \\
(\text { St dev })^{\mathrm{a}}\end{array}$ & Men\% ${ }^{a}$ & Description & Quality $^{c}$ \\
\hline & & & & & & $\begin{array}{l}\text { double-blind, placebo-con- trolled study of a } \\
\text { cognition-enhancing agent called Synaptoclear }\end{array}$ & \\
\hline 2005, Palmer [33] & 71 & 35 & 36 & $\begin{array}{l}65.7(5.2) \\
70.9(6.2)\end{array}$ & $\begin{array}{l}57.1 \\
97.2\end{array}$ & $\begin{array}{l}\text { Cases: } 35 \text { clinically stable outpatients with diagnoses } \\
\text { of schizophrenia (30) or schizoaffective disorder (5). } \\
\text { Controls: } 36 \text { outpatients with diabetes mellitus, } \\
\text { recruited through clinical research programs Answers } \\
\text { regarding participation in a randomised controlled } \\
\text { trial for an experimental compound ("plakmin"), } \\
\text { tested for cognitive-enhancing effects, which was } \\
\text { modelled after a local study that tested the cognitive } \\
\text { benefits of a cholinomimetic agent }\end{array}$ & 5 \\
\hline 2007, Palmer [37] & 59 & 31 & 28 & $\begin{array}{l}52.4(7) \\
56.6(11.1)\end{array}$ & $48.4,46.4$ & $\begin{array}{l}\text { Cases: } 31 \text { outpatients with schizophrenia. Controls: } \\
\text { recruited from the community (28) Answers } \\
\text { regarding a longitudinal study of side effects, } \\
\text { including tardive dyskinesia, of FDA-approved } \\
\text { second-generation antipsychotic medications } \\
\text { among middle-aged and older patients }\end{array}$ & 5.5 \\
\hline 2015, Wang [38] & 128 & 100 & 28 & $\begin{array}{l}35.85(11.21) \\
45.68(11.54)\end{array}$ & 56,53 & $\begin{array}{l}\text { Cases: both inpatients and outpatients. Controls: } \\
\text { community volunteers Answers regarding the } \\
\text { participation to a hypothetical clinical trial }\end{array}$ & 4.5 \\
\hline
\end{tabular}

${ }^{a}$ statistics for both schizophrenia patients and controls, separated by a comma

$\mathrm{b}_{\text {italic lines - decision-making capacity after using enhancement techniques }}$

${ }^{c}$ Newcastle-Ottawa Scale for case-control studies

a decreased reasoning in schizophrenia patients was almost four times higher compared to the control groups $(\mathrm{OR}=0.27, \mathrm{CI}=0.17-0.42, p<0.001)$. See Fig. 4 for details. Publication bias was not statistically significant (Egger's regression intercept $=1.73, p=0.11$ ). The heterogeneity of the reasoning dimension was small $\left(\mathrm{I}^{2}=10.8 \%\right)$.

An increase in the percentage of men in the schizophrenia group caused a statistically significant decrease in the difference in means between the cases and control groups (see Table 3 and Fig. 5). The difference between mean values for reasoning in the cases and control groups was larger for studies conducted outside the US ( -2 , with limits between -4.14 and 0.14 ) compared to studies performed in the US $(-1.09$, with limits between -1.53 and -0.64$)$. The difference was statistically significant $(Z=-7.021, p<$ 0.001).

Three studies contained information about EIC. In them, we found a non-statistically significant decrease in the difference in means compared to controls $(-0.830$, with limits between -2.28 and 0.57 ). The odds for a decreased reasoning in schizophrenia subjects using EIC was four times higher compared to the control groups $(\mathrm{OR}=0.26, \mathrm{CI}=0.03-2.60, p=0.250)$, but the result was not statistically significant.

The use of EIC leads to a significant increase in understanding in schizophrenia subjects compared to standard informed consent forms $(\mathrm{Z}=-5.05, p<0.001)$.

\section{Expressing a choice}

The effect size was significant, with a difference in means of $-0.05(-0.9,-0.01, p=0.022)$. See Fig. 6 for details. The odds for a decreased aptitude to express a choice in schizophrenia patients was about 66\% higher compared to the control groups $(\mathrm{OR}=0.62, \mathrm{CI}=0.48$ $0.80, p<0.001)$. Publication bias was not statistically significant (Egger's regression intercept $=0.14, p=0.89$ ). The heterogeneity of the aptitude to express a choice was very low $\left(\mathrm{I}^{2}=0\right)$.

By running a meta-regression using mean age, percent of men and percent of inpatient status we could not find any statistically significant differences (see Table 3 ).

Table 2 Mean scores for the included studies computed as simple arithmetic means

\begin{tabular}{llllll}
\hline Parameter & $\begin{array}{l}\text { Standard Informed } \\
\text { Consent, Cases }\end{array}$ & $\begin{array}{l}\text { Standard Informed } \\
\text { Consent, Controls }\end{array}$ & $\begin{array}{l}\text { Mean } \\
\text { values }\end{array}$ & $\begin{array}{l}\text { Enhanced Informed } \\
\text { Consent, Cases }\end{array}$ & $\begin{array}{l}\text { Enhanced Informed } \\
\text { Consent, Controls }\end{array}$ \\
\hline Understanding & 17.8 & 23.7 & 20.16 & 22.29 & 25.13 \\
Appreciation & 3.98 & 5.36 & 4.53 & 5.03 & 5.61 \\
Reasoning & 4.96 & 6.18 & 5.45 & 5.46 & 5.63 \\
Expressing a choice & 1.90 & 1.97 & 1.93 & 1.99 & 1.99 \\
Total No. of Subjects & 582 & 389 & & 102 & 69 \\
\hline
\end{tabular}




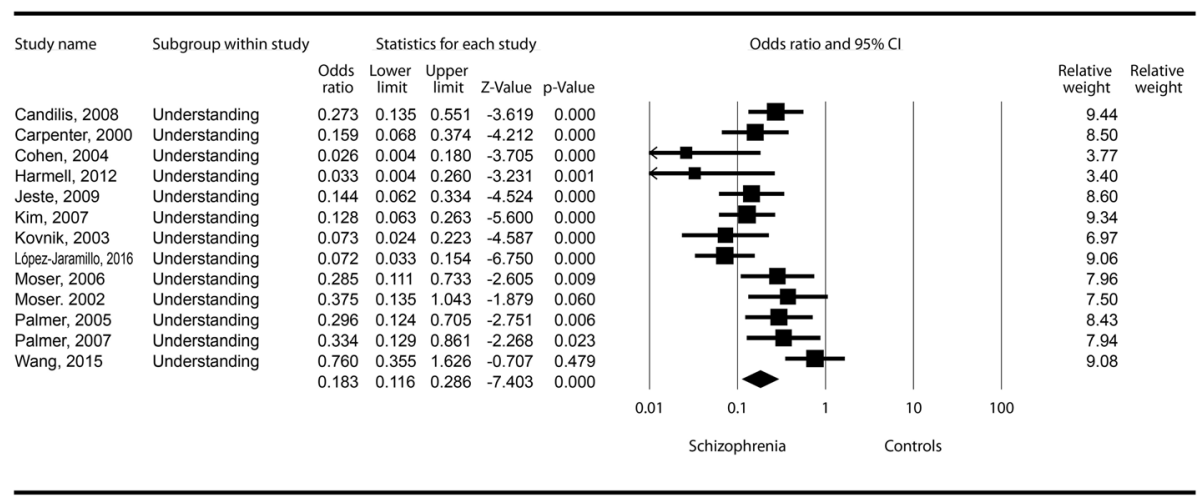

Meta Analysis

Fig. 2 Understanding - Forest plot for ORs

Three studies contained information about EIC. In them, we found a non-statistically significant increase in the difference in means compared to controls $(0.01$, with limits between -0.03 and 0.5 ). The odds for a decreased capacity to express a choice in schizophrenia subjects using the EIC was similar to the one found in the control groups $(\mathrm{OR}=1.09, \mathrm{CI}=0.62-1.91, p=0.76)$.

The use of EIC forms leads to a significant increase in the aptitude to express a choice compared to standard informed consent forms $(\mathrm{Z}=-3.163, p=0.002)$.

\section{Discussions}

Our study showed that, when using non-enhanced informed consent procedures, schizophrenia subjects tend to have significantly decreased values for all dimensions of DMC, the highest effect sizes being encountered for the understanding and reasoning sub-scales.

Psychiatry patients are considered a vulnerable population in clinical research, and their inclusion in a trial can be done only in particular circumstances. For example, the CIOMS guidelines state that research involving individuals who, by reason of mental or behavioral disorders are not capable of giving adequately informed consent, can only be done if there are no other subjects that could be equally involved in that particular trial, and who are able to give an adequately informed consent [28]. Therefore, to include subjects in clinical trials, the investigators must make a binary decision about the presence/absence of DMC. Some studies recommend various threshold values for some or all DMC parameters [22, 29]. For example, in the Clinical Antipsychotic Trials of Intervention Effectiveness - Schizophrenia (CATIE) study [30], the investigators established a threshold value of 15 for the understanding scale, a value that was proven to be a little too conservative [22]. Our study showed that there is a circa 4-point difference between schizophrenia and control subjects in the understanding scale. If we were to take into account the mean value for understanding (20.16, see Table 2 ) and add to this the average difference obtained in the meta-analysis $(-4.43)$, we would see that the mean theorised value for the schizophrenia subjects [20.16-(4.43/2) $=17.95]$ is well above this threshold. Similarly, the lower limit with a $95 \%$ CI $(-5.76$, corresponding to a lower limit for the schizophrenia group of 18.06) is well above the 15 points threshold. By also considering the results of Kim et al. [22], our analysis emphasizes the idea that schizophrenia patients should be considered, per prima facie, as being able to make informed decisions regarding their participation to clinical trials. By assuming decision-making incapacity in these patients, we might discriminate them based on their disease; therefore, by trying to obey the bioethical principle of autonomy, we might breach the principle of justice.

Jeste et al. suggested the presence of a high intergroup heterogeneity in DMC for patients with schizophrenia, with a standard deviation often increased twofold compared to the control groups, and hinted as one

Table 3 Meta regression analysis

\begin{tabular}{llll}
\hline & Percent Men (B, Z) & Mean age in the schizophrenia group (B, Z) & Inpatient status (B, Z) \\
\hline Understanding & $-0.02,-1.56$ & $-0.01,-0.56$ & $-0.002,-0.33$ \\
Appreciation & $-0.007,-0.79$ & $-0.002,-0.12$ & $-0.005,-1.15$ \\
Reasoning & $-0.02,-2.54$ & $0.01,0.43$ & $-0.002,-0.29$ \\
Expressing a choice & $-0.004,-0.55$ & $0.008,0.58$ & $-0.000,-0.11$ \\
\hline
\end{tabular}

$B$ Beta coefficient, $Z Z$-value, Italicized cells - statistically significant results 


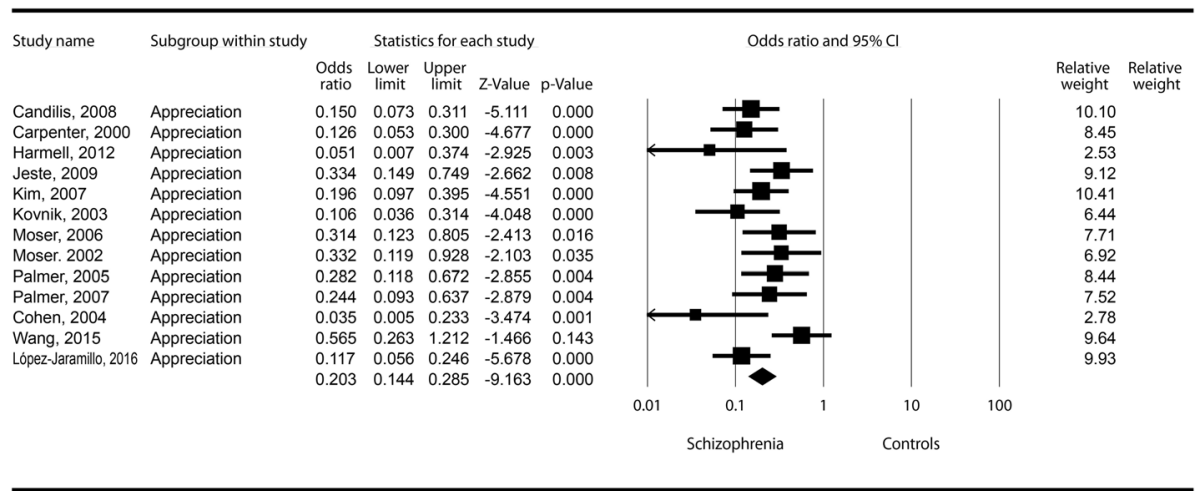

Meta Analysis

Fig. 3 Appreciation - Forest plot for ORs

of its leading sources the variable inclusion of in- and outpatients in the cases groups [3]. Our analysis failed to confirm his hypothesis, as all four dimensions of decisionmaking capacity were insignificantly affected by the percentage of inpatients included in the initial studies. Also, our analysis showed a little heterogeneity between studies, suggesting an excellent reliability of the results.

The scores on every subscale decreased once the percentage of men in the schizophrenia group increased, but the result did failed to reach statistical significance (except for the reasoning subscale). This failure could be generated either by a low number of studies included in the analysis, or an actual absence of an association between gender and decision capacity. Some studies published in the scientific literature showed that women have a better social adaptability to the disease. Hintikka et al. found that women with schizophrenia have significantly better independent skills and domestic activities compared to men with the same illness. For example, $11 \%$ of men lacked skills regarding personal hygiene compared to only $4 \%$ of the women; $32 \%$ of men lacked skills regarding financial affairs compared to $20 \%$ in women; $25 \%$ of men lacked decision-making capacity compared to only $19 \%$ in women [14]. Hambrecht et al. showed that maladaptive social behaviours (including negative symptoms or inappropriate illness behaviours) were more often found in men with schizophrenia [31]. Palmer and Jeste revealed that understanding is correlated with the severity of negative symptoms [32]. However, more studies are needed before we can definitely associate (or fail to associate) gender with decreased decision capacity in schizophrenia patients.

Various studies have suggested that age could alter decision-making capacity in schizophrenia patients (see e.g. [32]). Our study showed that there might be an agerelated deterioration in various MacCAT-CR subscales, but we could not prove it with statistical significance. This failure could be generated either by a low number of studies included in the analysis, or an actual absence of an association between age and decision capacity.

Using EICs, various authors proved a significant increase in DMC $[13,20,21]$. Our study shows that, compared to the control group, EICs decreased the deficits in the understanding, reasoning and appreciation subscales. When

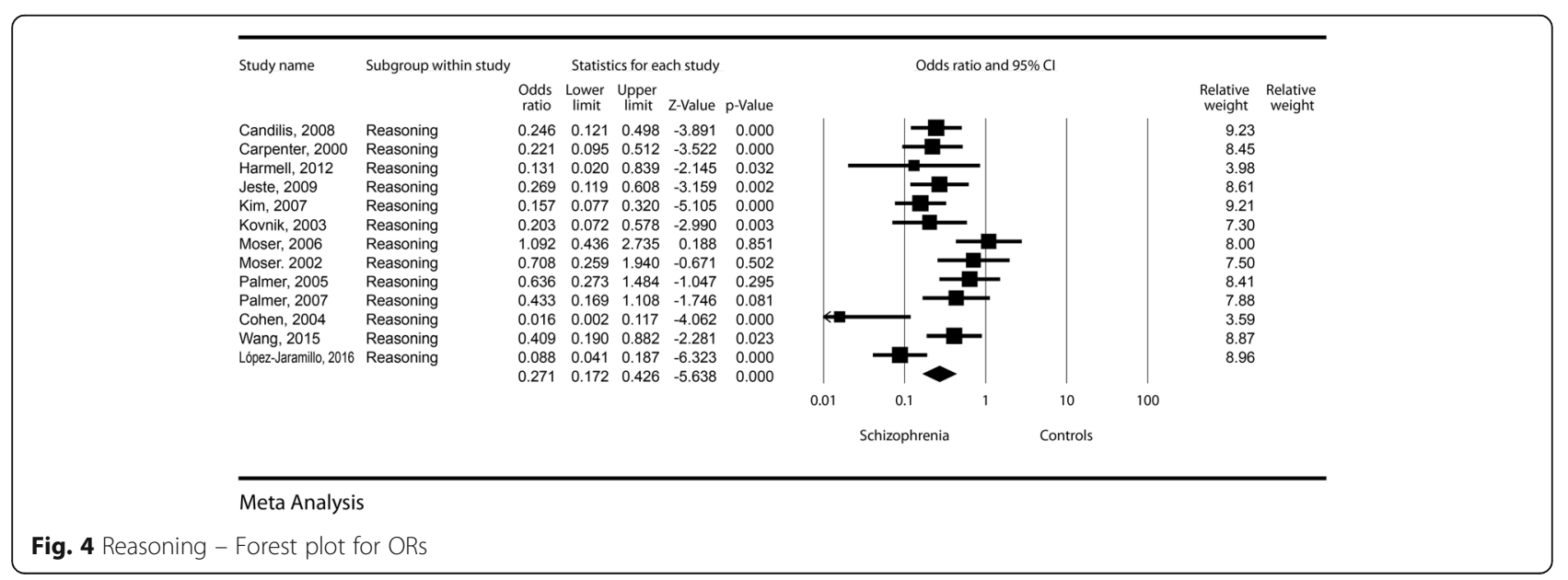




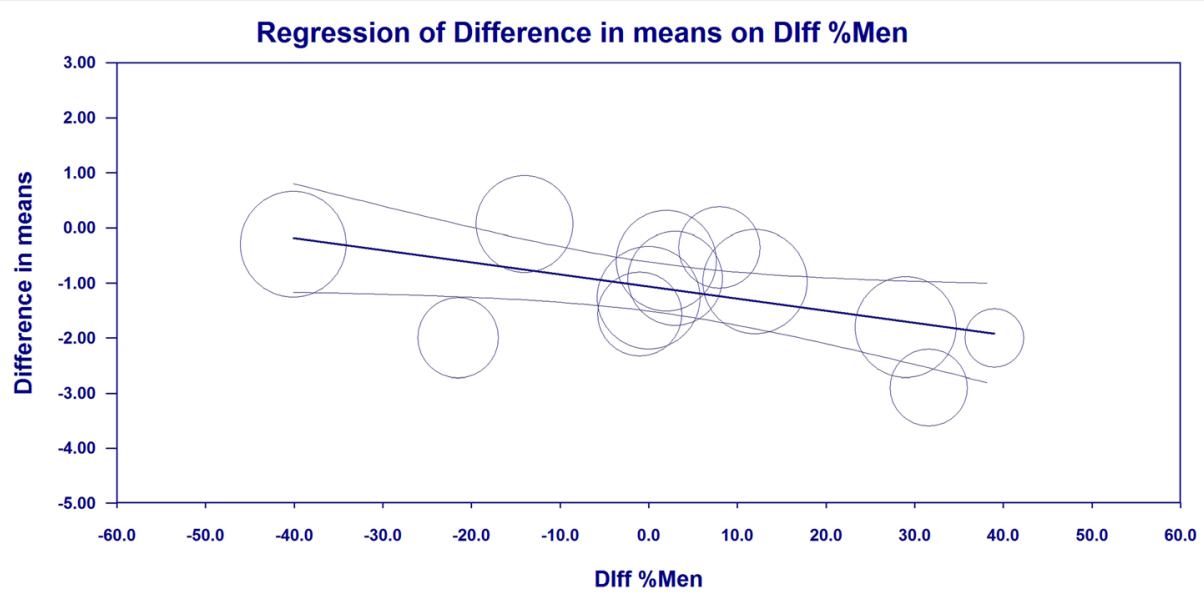

Fig. 5 Reasoning - meta-regression, age of schizophrenia subjects

compared to standard consent studies, EICs significantly increased the values for all four MacCAT-CR subscales. Based on these results, we recommend using EICs especially in clinical trials that require subjects with severe cognitive deficits.

Kim et al. found that understanding sub-scale from MacCAT-CR was more important as a predictor of a categorical capacity status compared to appreciation or reasoning [22]. Most instruments used for assessing the decision-making capacity only test the understanding (for details see Palmer et al. [33]). Our study shows that reasoning, together with understanding are the most affected dimensions of decision-making capacity in schizophrenia subjects, and therefore, tasks directed specifically toward increasing them might be the best approach in optimising the decision-making capacity for potential subjects with schizophrenia and decision-making incapacity. Additionally, if researchers would like to simplify DMC analysis, reasoning should be tested alongside understanding to improve the accuracy of the outcome.

The results of this article could be used by clinical researchers to better fine-tune the selection criteria for inclusion in clinical trials, and by the Institutional Ethics Committees to verify the compliance of the study protocol with the general and specific ethical principles of clinical research.

\section{Limits}

The number of studies included in the analysis is small (13); however, if we were to include studies in which decision-making capacity was evaluated using other scales, the results would have been more heterogeneous, mainly due to the usage of distinct methodologies for assessing DMC. Moreover, only three studies included data about enhanced ways of informing potential subjects. Even if the number was small, the results reached statistical significance in most scales, suggesting that they profoundly improved DMC. Only two studies were performed outside US, potentially making the results geographically biased. Therefore, they should be interpreted with caution in significantly different population groups. Also, the comparisons US-outside US should be regarded as potentially having poor error estimation.

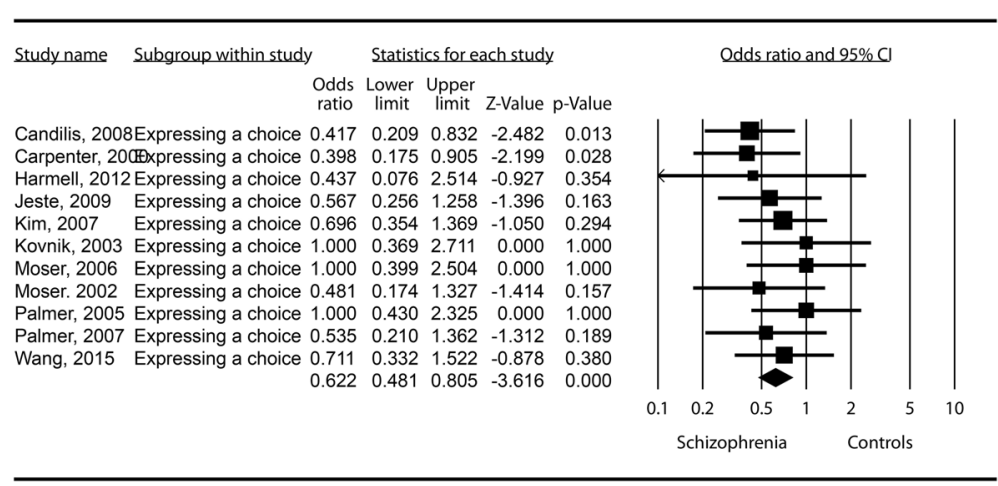

Meta Analysis

Fig. 6 Expressing a choice - Forest plot for ORs 


\section{Conclusions}

Even if schizophrenia patients have a significantly decreased decision-making capacity compared to non-mentally-ill controls, they should be considered as competent unless very severe changes are identifiable during clinical examination. Enhanced informed consent forms decrease the differences between schizophrenia patients and nonmentally-ill controls (except for the reasoning dimension) and should be used whenever the investigators want to include more ill patients in their clinical trials. Increased age, men gender and an increased percentage of inpatients might increase the differential of decision-making incompetence compared to non-mentally-ill subjects in various dimensions of the decision-making competence as analysed by the MacCAT-CR scale, but the small number of subjects did not allow us (except for one instance) to reach statistical significance.

\section{Abbreviations}

CATIE: Clinical Antipsychotic Trials of Intervention Effectiveness - Schizophrenia; CIOMS: Council for International Organizations of Medical Sciences; DMC: Decision making capacity; EIC: Enhanced informed consent; MacCAT-CR: MacArthur Competence Assessment Tool for Clinical Research; NOS: Newcastle-Ottawa scale; OR: Odds Ratio

\section{Acknowledgements}

Not applicable.

\section{Funding}

The article received no specific fund support.

\section{Availability of data and materials}

Not applicable.

\section{Authors' contributions}

$\mathrm{SH}$ - drafted the framework of the article, was involved in its design, statistical analysis, drafting the manuscript and approving the final version. MCR - was involved in the statistical analysis, database research, reviewing and correcting the manuscript, and approving the final version. $\mathrm{IN}$ - was involved in the statistical analysis, database research, reviewing the manuscript for critical contents, and approving the final version. ED - was involved in database research, statistical analysis, writing parts of the discussion section, reviewing the manuscript and approving the final version.

\section{Ethics approval and consent to participate}

Not applicable.

\section{Consent for publication}

Not applicable.

\section{Competing interests}

The authors declare that they have no competing interests.

\section{Publisher's Note}

Springer Nature remains neutral with regard to jurisdictional claims in published maps and institutional affiliations.

\section{Author details}

${ }^{1}$ Carol Davila University of Medicine and Pharmacy, Sos.Vitan Barzesti 9, 042122 Sector 4, Bucuresti, Romania. ${ }^{2}$ National Institute of Legal Medicine, Bucharest, Romania. ${ }^{3}$ University of Medicine and Pharmacy, Galați, Romania.
Received: 26 May 2017 Accepted: 14 December 2017

Published online: 05 January 2018

\section{References}

1. Hostiuc S. Informed consent [Consimțământul informat]. Cluj-Napoca: Casa Cărții de Știință; 2014.

2. Koren D, Poyurovsky M, Seidman LJ, Goldsmith M, Wenger S, Klein EM. The neuropsychological basis of competence to consent in first-episode schizophrenia: a pilot metacognitive study. Biol Psychiatry. 2005;57(6):609-16.

3. Jeste DV, Depp CA, Palmer BW. Magnitude of impairment in decisional capacity in people with schizophrenia compared to normal subjects: an overview. Schizophr Bull. 2006;32(1):121-8.

4. Combs DR, Adams SD, Wood TD, Basso MR, Gouvier WD. Informed consent in schizophrenia: the use of cues in the assessment of understanding. Schizophr Res. 2005;77(1):59-63.

5. Appelbaum PS. Assessment of patients' competence to consent to treatment. N Engl J Med. 2007;357(18):1834-40.

6. Appelbaum PS, Roth LH. Competency to consent to research: a psychiatric overview. Arch Gen Psychiatry. 1982;39(8):951.

7. Beauchamp T, Childress J. Principles of biomedical ethics. Oxford: Oxford University Press; 2005.

8. Hein IM, Troost PW, Lindeboom R, Benninga MA, Zwaan CM, van Goudoever JB, Lindauer RJ. Accuracy of the MacArthur competence assessment tool for clinical research (MacCAT-CR) for measuring children's competence to consent to clinical research. JAMA Pediatr. 2014:168(12):1147-53.

9. Kim SY, Karlawish JH, Caine ED. Current state of research on decisionmaking competence of cognitively impaired elderly persons. Am J Geriatr Psychiatry. 2002;10(2):151-65.

10. Sessums $L L$, Zembrzuska $H$, Jackson JL. Does this patient have medical decision-making capacity? JAMA. 2011;306(4):420-7.

11. Wilson ST, Stanley B. Ethical concerns in schizophrenia research: looking back and moving forward. Schizophr Bull. 2006;32(1):30-6.

12. Howe V, Foister K, Jenkins K, Skene L, Copolov D, Keks N. Competence to give informed consent in acute psychosis is associated with symptoms rather than diagnosis. Schizophr Res. 2005;77(2-3):211-4.

13. Moser DJ, Schultz SK, Arndt S, Benjamin ML, Fleming FW, Brems CS, Paulsen JS, Appelbaum PS, Andreasen NC. Capacity to provide informed consent for participation in schizophrenia and HIV research. Am J Psychiatry. 2002; 159(7):1201-7.

14. Hintikka J, Saarinen P, Tanskanen A, Koivumaa-Honkanen H, Viinamäki H. Gender differences in living skills and global assessment of functioning among outpatients with schizophrenia. Aust N Z J Psychiatry. 1999; 33(2):226-31

15. Kovnick JA, Appelbaum PS, Hoge SK, Leadbetter RA. Competence to consent to research among long-stay inpatients with chronic schizophrenia. Psychiatr Serv. 2003:54(9):1247-52.

16. Appelbaum PS, Grisso T: MacArthur competence assessment tool for clinical research (MacCAT-CR): professional resource press/professional resource exchange; 2001.

17. Anderson KK, Mukherjee SD. The need for additional safeguards in the informed consent process in schizophrenia research. J Med Ethics. 2007 33(11):647-50

18. Candilis PJ, Fletcher KE, Geppert CM, Lidz CW, Appelbaum PS. A direct comparison of research decision-making capacity: schizophrenia/ schizoaffective, medically ill, and non-ill subjects. Schizophr Res. 2008; 99(1-3):350-8.

19. Carpenter WT Jr, Gold JM, Lahti AC, Queern CA, Conley RR, Bartko JJ, Kovnick J, Appelbaum PS. Decisional capacity for informed consent in schizophrenia research. Arch Gen Psychiatry. 2000;57(6):533-8.

20. Harmell AL, Palmer BW, Jeste DV. Preliminary study of a web-based tool for enhancing the informed consent process in schizophrenia research. Schizophr Res. 2012;141(2-3):247-50.

21. Jeste DV, Palmer BW, Golshan S, Eyler LT, Dunn LB, Meeks T, Glorioso D, Fellows I, Kraemer H, Appelbaum PS. Multimedia consent for research in people with schizophrenia and normal subjects: a randomized controlled trial. Schizophr Bull. 2009;35(4):719-29.

22. Kim SY, Appelbaum PS, Swan J, Stroup TS, McEvoy JP, Goff DC, Jeste DV, Lamberti JS, Leibovici A, Caine ED. Determining when impairment constitutes incapacity for informed consent in schizophrenia research. $\mathrm{Br}$ Psychiatry. 2007;191:38-43. 
23. Wang SB, Wang YY, Ungvari GS, Ng CH, Wu RR, Wang J, Xiang YT. The MacArthur Competence Assessment Tools for assessing decision-making capacity in schizophrenia: a meta-analysis. Schizophr Res. 2017;31;183:56-63. making capacity in schizophrenia: a meta-analysis. Schizophr Res. 2016;

24. Dunn LB, Jeste DV. Enhancing informed consent for research and treatment. Neuropsychopharmacology. 2001;24(6):595.

25. Flory J, Emanuel E. Interventions to improve research participants' understanding in informed consent for research: a systematic review. JAMA. 2004;292(13):1593-601

26. Holmes-Rovner M, Wills CE. Improving informed consent: insights from behavioral decision research. Med Care. 2002:40(9):V-30-8.

27. Stang A. Critical evaluation of the Newcastle-Ottawa scale for the assessment of the quality of nonrandomized studies in meta-analyses. Eur 」 Epidemiol. 2010;25(9):603-5.

28. Sciences $\mathrm{CflO}$ oM. International ethical guidelines for biomedical research involving human subjects. Bull Med Ethics. 2002;182:17.

29. Stroup S, Appelbaum P. The subject advocate: protecting the interests of participants with fluctuating decisionmaking capacity. IRB. 2003;25(3):9-11.

30. Stroup S, Appelbaum P, Swartz M, Patel M, Davis S, Jeste D, Kim S, Keefe R, Manschreck T, McEvoy J. Decision-making capacity for research participation among individuals in the CATIE schizophrenia trial. Schizophr Res. 2005; 80(1):1-8.

31. Hambrecht M, Maurer K, Häfner H. Gender differences in schizophrenia in three cultures. Soc Psychiatry Psychiatr Epidemiol. 1992;27(3):117-21.

32. Palmer BW, Jeste DV. Relationship of individual cognitive abilities to specific components of decisional capacity among middle-aged and older patients with schizophrenia. Schizophr Bull. 2006;32(1):98-106.

33. Palmer BW, Dunn LB, Appelbaum PS, Mudaliar S, Thal L, Henry R, Golshan S, Jeste DV. Assessment of capacity to consent to research among older persons with schizophrenia, Alzheimer disease, or diabetes mellitus: comparison of a 3-item questionnaire with a comprehensive standardized capacity instrument. Arch Gen Psychiatry. 2005;62(7):726-33.

34. Cohen BJ, McGarvey EL, Pinkerton RC, Kryzhanivska L. Willingness and competence of depressed and schizophrenic inpatients to consent to research. J Am Acad Psychiatry Law. 2004;32(2):134-43.

35. López-Jaramillo C, Aristizábal Tobler C, Ovalle Gómez C, Escobar Triana J. Correlation between insight and capacity to consent to research in subjects with bipolar disorder type I and schizophrenia. Rev Colomb Psiquiatr. 2016; 45(3):194-200.

36. Moser DJ, Reese RL, Hey CT, Schultz SK, Arndt S, Beglinger LJ, Duff KM, Andreasen NC. Using a brief intervention to improve decisional capacity in schizophrenia research. Schizophr Bull. 2006;32(1):116-20.

37. Palmer BW, Dunn LB, Depp CA, Eyler LT, Jeste DV. Decisional capacity to consent to research among patients with bipolar disorder: comparison with schizophrenia patients and healthy subjects. J Clin Psychiatry. 2007;68(5):689-96.

38. Wang X, Yu X, Tang H, Lan T, Yao G, Si T, Wang H, Li T, Yu L. Reliability and validity of Chinese mandarin version of MacArthur competence assessment tool for clinical research in patients with schizophrenia. Chin J Psychiatry. 2015;48(1):17-22.

\section{Submit your next manuscript to BioMed Central and we will help you at every step:}

- We accept pre-submission inquiries

- Our selector tool helps you to find the most relevant journal

- We provide round the clock customer support

- Convenient online submission

- Thorough peer review

- Inclusion in PubMed and all major indexing services

- Maximum visibility for your research

Submit your manuscript at www.biomedcentral.com/submit
Biomed Central 